\title{
Factors associated with failure of emergency wait-time targets for high acuity discharges and intensive care unit admissions
}

\author{
Ivy Cheng, MD, MSc, PhD*Æ§; Merrick Zwarenstein, MD, MSc, PhD"; Alex Kiss, PhD $^{\dagger}$; Maaret \\ Castren, MD, PhD"; Mats Brommels, MD, PhD**; Michael Schull, MD, $\mathrm{MSc}^{\dagger}$
}

\section{ABSTRACT}

Objective: Ontario established emergency department lengthof-stay (EDLOS) targets but has difficulty achieving them. We sought to determine predictors of target time failure for discharged high acuity patients and intensive care unit (ICU) admissions.

Methods: This was a retrospective, observational study of 2012 Sunnybrook Hospital emergency department data. The main outcome measure was failing to meet government EDLOS targets for high acuity discharges and ICU emergency admissions. The secondary outcome measures examined factors for low acuity discharges and all admissions, as well as a run chart for 2015 - 2016 ICU admissions. Multiple logistic regression models were created for admissions, ICU admissions, and low and high acuity discharges. Predictor variables were at the patient level from emergency department registries.

Results: For discharged high acuity patients, factors predicting EDLOS target failure were having physician initial assessment duration (PIAD) $>2$ hours (OR 5.63 [5.22-6.06]), consultation request (OR 10.23 [9.38-11.14]), magnetic resonance imaging (MRI) (OR 19.33 [12.94-28.87]), computed tomography (CT) (OR 4.24 [3.92-4.59]), and ultrasound (US) (OR 3.47 [3.13-3.83]). For ICU admissions, factors predicting EDLOS target failure were bed request duration (BRD) $>6$ hours (OR 364.27 [43.20-3071.30]) and access block $(A B)>1$ hour (OR 217.27 [30.62-1541.63]). For discharged low acuity patients, factors predicting failure for the 4-hour target were PIAD $>2$ hours (OR 15.80 [13.3518.71]), consultation (OR 20.98 [14.10-31.22]), MRI (OR 31.68 [6.03-166.54]), CT (OR 16.48 [10.07-26.98]), and troponin I (OR 13.37 [6.30-28.37]).

Conclusion: Sunnybrook factors predicting failure of targets for high acuity discharges and ICU admissions were hospitalcontrolled. Hospitals should individualize their approach to shortening EDLOS by analysing its patient population and resource demands.

\section{RÉSUMÉ}

Objectif: Des cibles de durée de séjour (DS) au service des urgences (SU) ont été fixées en Ontario, mais elles sont difficiles à respecter. Aussi avons-nous tenté de déterminer des facteurs prévisionnels du non-respect des cibles de temps en ce qui concerne les sorties de patients atteints d'une affection grave ainsi que les admissions au service des soins intensifs (SSI).

Méthode: II s'agit d'une étude d'observation, rétrospective, reposant sur des données qui concernent le SU du Sunnybrook Hospital, en 2012. Le principal critère d'évaluation consistait dans le non-respect des cibles de la DS au SU, fixées par le gouvernement en ce qui concerne les sorties de patients atteints d'une affection grave et les admissions au SSI depuis le SU. Les critères d'évaluation secondaires portaient sur les facteurs concernant les sorties de patients atteints d'une affection peu grave et toutes les hospitalisations, ainsi que le graphique des séquences représentant les admissions au SSI, en 2015-2016. Des modèles de régression logistique multiple ont été élaborés relativement aux admissions, aux admissions au SSI ainsi qu'aux sorties de patients atteints d'une affection grave ou d'une affection peu grave. Les variables prévisionnelles ont été établies au niveau des patients, à l'aide de données inscrites dans les registres des SU.

Résultats: En ce qui concerne la sortie de patients atteints d'une affection grave, les facteurs prévisionnels du nonrespect des cibles de la DS au SU comprenaient : une durée de l'évaluation médicale initiale (EMI) > 2 h (RRA : 5,63 [5,22$6,06]$ ), les demandes de consultation (risque relatif approché [RRA] : 10,23 [9,38-11,14]), les examens par imagerie par résonance magnétique (IRM) (RRA : 19,33 [12,94-28,87]), les tomodensitométries (TDM) (RRA : 4,24 [3,92-4,59]) et les échographies (RRA : 3,47 [3,13-3,83]). Quant aux admissions au SSI, les facteurs prévisionnels du non-respect des cibles de la DS au SU étaient : une durée de demande de lits $>6 \mathrm{~h}$ (RRA :

From the *Emergency Services and Institute of Clinical Evaluative Sciences (ICES), Sunnybrook Health Sciences Center, University of Toronto, Toronto, ON; ‡Department of Clinical Science and Education, Sodersjukhuset-Karolinska Institutet, Stockholm, Sweden; §Department of Medicine, University of Toronto, Toronto, ON; đDepartment of Family Medicine, Schulich School of Medicine and Dentistry, Western University, London, ON; IMedical Director of Emergency Care, Helsinki University, Helsinki, Finland; and the ** Medical Management Center, Department of Learning, Informatics, Management and Ethics, Karolinska Institutet, Stockholm, Sweden.

Correspondence to: Dr. Ivy Cheng, Assistant Professor, Department of Medicine, Sunnybrook Health Sciences Center, University of Toronto, Toronto, ON; Email: ivy.cheng@sunnybrook.ca. 
364,27 [43,20-3071,30]) et un délai d'attente d'un lit $>1 \mathrm{~h}$ (RRA : 217,27 [30,62-1541,63]). Enfin, pour ce qui est de la sortie de patients atteints d'une affection peu grave, les facteurs prévisionnels du non-respect de la cible de $4 \mathrm{~h}$ incluaient : une $E M I>2 h$ (RRA : 15,80 [13,35-18,71]), les consultations (RRA : 20,98 [14,10-31,22]), les examens par IRM (RRA : $31,68[6,03-166,54])$, les TDM (RRA : 16,48 [10,07-26,98]) et les dosages de la troponine I (RRA : 13,37 [6,30-28,37]).

Conclusions: Les facteurs prévisionnels du non-respect des cibles de temps pour les sorties de patients atteints d'une affection grave et pour les admissions au SSI au Sunnybrook Hospital relevaient de l'établissement. Aussi faudrait-il adapter, dans chaque hôpital, le processus de réduction de la $\mathrm{DS}$ en fonction des résultats d'analyses de la population malade et des exigences en matière de ressources.

Keywords: emergency department crowding factors, pay for performance time targets, quality improvement, health systems research

\section{INTRODUCTION}

\section{Background}

Irrespective of the health care system, emergency department (ED) crowding is an international problem $^{1-11}$ and associated with increased patient morbidity and mortality, ${ }^{2,8,9,11,12}$ especially amongst the elderly. ${ }^{13}$ Although crowding is a long-standing problem, ${ }^{4}$ there is still no common solution, ${ }^{3,14}$ and proposed interventions lack a robust evidence base. ${ }^{3,5,14-16}$

The search for solutions is hampered by the absence of a common definition, ${ }^{3,17}$ the multifactorial, complex causes, ${ }^{1-5,18-20}$ and by public $^{21}$ and physician misperception $^{22}$ of crowding. The major contributing cause of crowding is access block (AB), where no hospital bed is available for patients assessed in the $\mathrm{ED}$ requiring admission. ${ }^{5,8,9,20,22-29}$ Other causes include other input, throughput, and output system factors. ${ }^{18,19}$

\section{Importance}

Many jurisdictions have implemented policies with targets for emergency department length of stay (EDLOS), but if a hospital wishes to improve EDLOS it is unclear which interventions should be implemented. Knowledge transfer between hospitals and health care systems is challenging given different infrastructures ${ }^{3,20,30}$ and the limited evidence base supporting one intervention over another. To be evidence-based, the first step is to find the factors associated with prolonged EDLOS for the hospital. ${ }^{30}$ With these data, operations can focus on modifiable factors and determine solutions by a systems approach. ${ }^{31-33}$

\section{Goals of this investigation}

The primary objective of this study was to provide insight into factors associated with failing to meet the
Ontario Ministry of Health (Ministry) EDLOS targets for high acuity patients discharged from the ED and patients admitted to the intensive care unit (ICU) from the ED. The secondary objectives were to determine the factors associated with prolonged EDLOS at the Sunnybrook Health Sciences Centre (Sunnybrook) in 2012 and to document a Plan-Do-Study-Act (PDSA) cycle for three interventions affecting ICU admissions' EDLOS and target achievement between 2015 and 2016. We focused on discharged high acuity patients because they comprised greater than $60 \%$ of Sunnybrook's ED patients, were sicker and consistently failed EDLOS government targets, whereas low acuity discharges succeeded. ICU admissions were targeted because this population was the fifth most consulted service, failed government targets, and had average EDLOS exceeding 12 hours associated with high mortality. ${ }^{34}$

\section{METHODS}

\section{Study setting and design}

This was a retrospective, single-centre, observational study. The study population was Sunnybrook emergency department patients from January 1 to December 31, 2012. Sunnybrook is an academic tertiary level hospital in Toronto, ON. Its emergency department received greater than 57,000 patients in 2012 with volumes increasing at $4 \%$ annually. By 2015, volumes were 60,685. It is a regional trauma, cancer, high risk maternal, neonatal, neurosurgical, interventional cardiology and stroke centre that serves mainly adults with $6 \%$ of patients $\leq 18$ years old and $34 \%$ $\geq 65$ years old. Onsite pediatric services are unavailable.

\section{Selection of participants, methods, and measurements}

Data were retrieved from four administrative databases: Electronic Patient Registry, Emergency Department 
Information Systems, Emergency Department Stretcher, and Hospital Occupancy Tables. These databases are necessary for patient registration and management. Emergency registration, physicians, nurses, and decision support enter data for each patient encounter. All patient visits were included, irrespective of multiple visits from the same patient at different times.

Using Stata (Version 13.1, StataCorp, College Station, TX), personnel checked administrative data for duplications, missing datapoints, and inaccurate times (e.g., negative durations or physician initial assessment duration $[\mathrm{PIAD}]>$ EDLOS). Erroneous duplicated entries of the same patient visit were removed. For missing and discrepant datapoints, chart reviews were performed (by IC) to find the information. If the datapoint was available through the chart, it was changed manually. If the data were still missing post chart review, they were defined as missing and excluded. All other data entries were included. Descriptive statistics were determined for selected variables.

The Canadian Triage and Acuity Scale (CTAS) recommends the ideal time for a physician to see the patient, ${ }^{35}$ not EDLOS. However, the Ministry uses the scale to define high (CTAS 1 to 3 ) and low acuity (CTAS 4 to 5) patients for its Pay for Results Program. ${ }^{36}$ Patients

\section{Table 1. Government classifications}

\section{Group}

Discharged home - low acuity (CTAS 4 and 5)

Discharged home - high acuity (CTAS 1 to 3 )

Admissions to hospital

Left without being seen by an emergency physician

Died

CTAS $=$ Canadian Triage and Acuity Scal $\mathrm{e}^{35}$ are grouped into the following government classifications with EDLOS targets for discharges (high and low acuity) and admissions (Table 1).

Discharged high acuity patients are discharged home with an acuity score between 1 and 3. ICU admissions are defined as hospital admissions under the ICU service.

Figure 1 outlines the durations of EDLOS, PIAD, bed request duration (BRD), and $A B . A B$ is defined as the duration waiting for the ward bed - specifically, the duration between bed request and departure time.

EDLOS factors were selected by literature searches, expert clinical consensus, ${ }^{1,4,8,20,29,37}$ and whether they were available in emergency administrative databases. Hospital-uncontrolled factors were patient factors such as demographics, acuity, ambulance arrival, shift, weekday/weekend, and patient volume by hour or day. Hospital-controlled factors were resources such as diagnostics, hospital occupancy, consultations, and physician initial assessment time.

\section{Outcomes}

The primary outcome was predicting failure of Ministry targets for discharged high acuity patients and ICU admissions. The secondary outcome was predicting EDLOS target failure for all Sunnybrook admissions and low acuity discharges in 2012, as well as documenting a PDSA cycle outlining three interventions that affected ICU EDLOS and reaching government targets between 2015 and 2016. In 2009-2010, the ideal EDLOS objective was that $90 \%$ of the low acuity discharges, high acuity discharges, and admissions achieve their respective targets of $\leq 4,8$, and 8 hours, respectively. By 2012, the Ministry changed to a 90th percentile EDLOS value of 4, 8, and 25 hours. Both targets were used in the analyses. For the

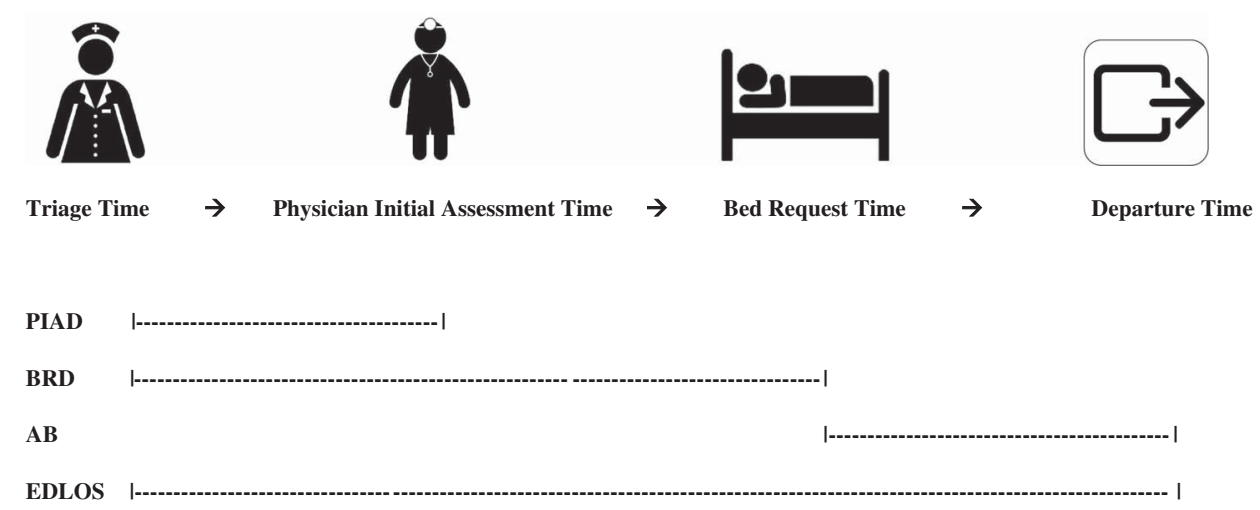

Figure 1. Durations: Physician Initial Assessment Duration (PIAD), Bed Request Duration (BRD), Access Block (AB), Emergency Department Length-of-Stay (EDLOS). 
PDSA cycle run chart, ICU admission volume, mean, and 90th percentile EDLOS were monitored at monthly increments for almost 2 years, during which the interventions occurred.

\section{Statistical analysis}

Stratified by discharged high acuity, discharged low acuity and admissions, multivariable logistic regression was performed. EDLOS was made binary by its disposition category and government targets: EDLOS $\leq 4,8$, and 8 hours for discharged low acuity, high acuity and admissions, respectively.

Determined by a literature search, factors were examined by two-by-two tables of odds ratios with the Woolf approximation for confidence intervals. Significant factors $(p<0.05)$ were chosen for multivariable logistic regression analyses. Models were derived by the forced entry, stepwise backwards method - keeping significant factors only $(p<0.05)$. The model with the lowest Akaike information criterion for best fit was chosen. To control for heteroskedasticity, models were run robust. Odds ratios were provided with their $95 \%$ confidence intervals.

By varying the combination of the top three factors associated with failure of targets, a descriptive, stepwise table of mean EDLOS +/- standard deviation and 90th percentile EDLOS was created for discharged high acuity patients and ICU admissions. The run chart plotted mean EDLOS by month. All analyses and descriptive statistics were performed with Stata.

Sunnybrook Research Ethics Board granted approval.

\section{RESULTS}

\section{Characteristics of study subjects}

From January 1 to December 31, 2012, there were 57,208 emergency patient visits to Sunnybrook. Less than $1 \%$ of datapoints were missing, duplicated, or discrepant. The median age was 53 years with more female visits than male. Greater than $85 \%$ were high acuity patients (CTAS 1 to 3). The emergency department received $23 \%$ of patients by ambulance. About $5.5 \%$ of patients bypassed the emergency physician and were direct to service, such as trauma, code stroke, or admission. The proportion of low acuity (CTAS 4 to 5) discharges, high acuity (CTAS 1 to 3 ) discharges, and admissions was $11.5 \%, 62.7 \%$, and $21.9 \%$, respectively. Among high acuity patients, $24.7 \%$ and $71.5 \%$ were admitted and discharged, respectively.
Overall consultation and admission rates were $26.5 \%$ and $22.3 \%$, respectively. Computed tomography (CT) scans and troponins were ordered on $20.4 \%$ and $22.6 \%$ of all patients, respectively (Table 2). The PDSA cycle for ICU admissions occurred between January 2015 and October 2016. During this time, there were three changes: 1) decrease of four ICU beds (April 2015), 2) ICU residents for consultation increased to two (August 2015), and 3) increase of four ward beds for patients transitioning from ICU (March 2016).

\section{MAIN RESULTS}

\section{Discharged high acuity patients}

The factors most associated with failing to meet the 8-hour time target were having a PIAD $>2$ hours or undergoing one of the following in the ED: consultation, CT scan, ultrasound (US), and a magnetic resonance imaging (MRI). Factors less strongly associated with failing to meet the 8-hour target included arrival by ambulance, being direct-to-service, being seen on an evening shift, nightshift, receiving an X-ray, troponin I, increasing emergency department stretcher occupancy with admissions, increasing daily volume, and increasing age (Table 3).

The 2012 Ministry's wait-time target for discharged high acuity patients was 90th percentile EDLOS of $\leq 8$ hours. Sunnybrook failed the target. The proportion of high acuity discharges having PIAD $>2$ hours, receiving a consultation, or CT was $47.5 \%, 12.2 \%$, and $16.7 \%$, respectively. In highacuity discharged patients where these factors were absent, all had EDLOS within the target time.

Table 4 outlines the effect of PIAD $>2$ hours, consultation, CT and MRI on EDLOS, and reaching government targets for discharged high acuity patients.

\section{ICU admissions}

Factors most associated with failure of meeting the 8 -hour time target were BRD greater than 6 hours and $\mathrm{AB}$ greater than 1 hour. Factors weakly associated with failure were being seen on a nightshift, percentage emergency medicine stretchers occupied by admissions per day, and patient arrival per hour. Having an acuity score of 1 and having an X-ray were variables predicting target achievement (see Table 3).

The 90th percentile of EDLOS for all ICU admissions was 28.8 hours, exceeding the Ministry target of 25 hours. There were three different possibilities to be admitted to 
Table 2. 2012 emergency patients - demographics, acuity, resource consumption, and disposition

Descriptor

Visits

Age

Female

Male

Acuity (CTAS)

1

2

3

High acuity (CTAS 1 to 3 )

4

5

Low acuity (CTAS 4 to 5)

Direct to consult service (bypassing emergency physician)

Arrive by ambulance

Consultation rate by directs and emergency physician

Consultations by emergency physician only

Diagnostic imaging

Total number of XR ordered

Total number of patients with $X R$

Total number of CTs ordered

Total number of patients with CT

Total number of US ordered

Total number of patients with US

Total number of MRI ordered

Total number of patients with MRI

Total number of nuclear tests ordered

Total number of patients with nuclear test

Total Number of Troponins

Discharges

All-comers admission rate

Directs admission rate

Ambulance arrival admission rate

Admissions discharged from the ED

Deaths

Deaths who arrived by ambulance

Left without being seen

Emergency department stretchers

Short stay unit stretchers

TOMX (percentage of ED stretcher occupied by admits per day)

Average

Minimum

Maximum

Number of hospital beds

Hospital occupancy

Average

Minimum

Maximum

Level 2 intensive care unit beds

Level 3 intensive care unit beds

Intensive care unit occupancy
57,208

53 [IQR: $34-72]$

$54.8 \%(31,346)$

$45.2 \%(25,852)$

Admissions*

Discharges*

$666(25.4 \%)$

$10,266(61.9 \%)$

$24,958(80.6 \%)$

$35,890(71.5 \%)$

$6,305(93,7 \%)$

$268(89.6 \%)$

$6,573(93.6 \%)$

$5.5 \%(3,168)$

$23.0 \%(13,140)$

$26.5 \%(15,169)$

$26.1 \%(14,959)$

31,341

$40.7 \%(23,294)$

18,847

$20.4 \%(11,657)$

5,848

$7.2 \%(4,148)$

471

$0.8 \%(457)$

59

$0.1 \%(57)$

$22.6 \%(12,949)$

$73.8 \%(42,239)$

$22.3 \%(12757 / 57208)$

$67.1 \%(2125 / 3168)$

$47.4 \%(5,941)$

$1.8 \%(224)$

$0.2 \%(131)$

$93.9 \%(123 / 131)$

$3.6 \%(2,081)$

36

$51.8 \%$

$19.1 \%$

$82.6 \%$

Jan 1 - Jan 16

351

349

346

344

346

341

Sept 18 - Dec 31
$97.6 \%$

$80.6 \%$

$113.4 \%$

20

38

$96 \%$

$\mathrm{CT}=$ computed tomography; $\mathrm{CTAS}=$ Canadian Triage and Acuity Scale; MRI = magnetic resonance imaging; US = ultrasound; $\mathrm{XR}=\mathrm{X}$-ray

*Provides the number and percent of admissions and discharges by CTAS level (left-without-being-seen and deaths are not included). 
Failure of emergency wait-time targets in the ED

\begin{tabular}{|c|c|c|c|c|}
\hline & $\begin{array}{l}\text { Discharged CTAS } 4-5 \\
\quad(n=6573)\end{array}$ & $\begin{array}{l}\text { Discharged CTAS 1-3 } \\
\quad(n=35890)\end{array}$ & $\begin{array}{l}\text { All admissions } \\
(n=12533)\end{array}$ & $\begin{array}{l}\text { ICU admissions } \\
\quad(n=752)\end{array}$ \\
\hline \multicolumn{5}{|c|}{ Odds ratios (OR) } \\
\hline Variable & OR & OR & OR & OR \\
\hline & $\begin{array}{c}\text { EDLOS }>4 \mathrm{hrs} v \\
\text { EDLOS } \leq 4 \mathrm{hrs} \\
{[95 \% \mathrm{Cl}]}\end{array}$ & $\begin{array}{c}\text { EDLOS }>8 \mathrm{hrs} \text { v. } \\
\text { EDLOS } \leq 8 \mathrm{hrs} \\
{[95 \% \mathrm{Cl}]}\end{array}$ & $\begin{array}{c}\text { EDLOS }>8 \mathrm{hrs} \text { v. } \\
\text { EDLOS } \leq 8 \mathrm{hrs} \\
{[95 \% \mathrm{Cl}]}\end{array}$ & $\begin{array}{c}\text { EDLOS }>8 \mathrm{hrs} \text { v. } \\
\text { EDLOS } \leq 8 \mathrm{hrs} \\
{[95 \% \mathrm{Cl}]}\end{array}$ \\
\hline \multirow{2}{*}{ Age (year) } & 1.01 & 1.01 & 1.00 & NS \\
\hline & {$[1.01-1.01]$} & {$[1.01-1.01]$} & {$[1.00-1.01]$} & \\
\hline \multirow[t]{2}{*}{ Male v. female } & NS & 1.01 & NS & NS \\
\hline & & {$[1.01-1.01]$} & & \\
\hline Ambulance arrival v. & 2.04 & 1.58 & 1.16 & NS \\
\hline non-ambulance arrival & {$[1.51-2.77]$} & {$[1.45-1.72]$} & [1.02-1.32] & \\
\hline Direct v. non-direct & NS & $\begin{array}{c}1.38 \\
{[1.11-1.72]}\end{array}$ & NS & NS \\
\hline Weekday v. weekend & $\begin{array}{c}0.83 \\
{[0.71-0.99]}\end{array}$ & NS & NS & NS \\
\hline Daily volume (per patient) & NS & $\begin{array}{c}1.01 \\
{[1.01-1.01]}\end{array}$ & NS & NS \\
\hline $\begin{array}{l}\text { Patient arrival per hour } \\
\text { (per patient) }\end{array}$ & $\begin{array}{c}1.03 \\
{[1.00-1.06]}\end{array}$ & NS & NS & $\begin{array}{c}1.02 \\
{[1.00-1.03]}\end{array}$ \\
\hline TOMX & 1.01 & 1.01 & 1.01 & 1.02 \\
\hline (percent of ED stretcher occupied by admissions per day) & {$[1.01-1.02]$} & {$[1.00-1.01]$} & {$[1.01-1.02]$} & {$[1.01-1.04]$} \\
\hline Hospital occupancy (percent) & NS & NS & $\begin{array}{c}1.04 \\
{[1.03-1.06]}\end{array}$ & NS \\
\hline \multirow{2}{*}{$\begin{array}{l}\text { Shift: day (0800-1600 hrs) } \\
\quad \text { evening (1600-2400 hrs) }\end{array}$} & Reference & Reference & Reference & NS \\
\hline & NS & $\begin{array}{c}1.23 \\
{[1.14-1.32]}\end{array}$ & NS & NS \\
\hline \multirow[t]{2}{*}{ night $(2400-0800 \mathrm{hrs})$} & 2.83 & 2.15 & 1.97 & 1.88 \\
\hline & {$[2.13-3.77]$} & [1.96-2.35] & {$[1.64-2.36]$} & [1.03-3.44] \\
\hline $\begin{array}{l}\text { Physician encounter time }>2 \text { hrs } \\
\text { (PIA }>2 \text { hrs) (yes v. no) }\end{array}$ & $\begin{array}{c}15.80 \\
{[13.35-18.71]}\end{array}$ & $\begin{array}{c}5.63 \\
{[5.22-6.06]}\end{array}$ & $\begin{array}{c}1.42 \\
{[1.23-1.63]}\end{array}$ & NS \\
\hline \multicolumn{5}{|l|}{ Patient received: } \\
\hline Consultation (yes v. no) & $\begin{array}{c}20.98 \\
{[14.10-31.22]}\end{array}$ & $\begin{array}{c}10.23 \\
{[9.38-11.14]}\end{array}$ & $\begin{array}{c}1.88 \\
{[1.63-2.18]}\end{array}$ & NS \\
\hline Magnetic resonance imaging (yes v. no) & $\begin{array}{c}31.68 \\
{[6.03-166.54]}\end{array}$ & $\begin{array}{c}19.33 \\
{[12.94-28.87]}\end{array}$ & NS & NS \\
\hline Computed tomography (yes v. no) & $\begin{array}{c}16.48 \\
{[10.07-26.98]}\end{array}$ & $\begin{array}{c}4.24 \\
{[3.92-4.59]}\end{array}$ & $\begin{array}{c}1.61 \\
{[1.42-1.82]}\end{array}$ & NS \\
\hline Ultrasound (yes v. no) & $\begin{array}{c}7.61 \\
{[5.25-11.04]}\end{array}$ & $\begin{array}{c}3.47 \\
{[3.13-3.83]}\end{array}$ & NS & NS \\
\hline Troponin (yes v. no) & $\begin{array}{c}13.37 \\
{[6.30-28.37]}\end{array}$ & $\begin{array}{c}1.66 \\
{[1.54-1.79]}\end{array}$ & $\begin{array}{c}1.30 \\
{[1.13-1.48]}\end{array}$ & NS \\
\hline X-ray (yes v. no) & $\begin{array}{c}1.89 \\
{[1.62-2.20]}\end{array}$ & $\begin{array}{c}1.70 \\
{[1.58-1.82]}\end{array}$ & $\begin{array}{c}1.17 \\
{[1.03-1.32]}\end{array}$ & $\begin{array}{c}0.63 \\
{[0.40-0.98]}\end{array}$ \\
\hline $\begin{array}{l}\text { Bed request duration }>6 \text { hrs (BRD 6) } \\
\text { (yes v. no) }\end{array}$ & $\mathrm{n} / \mathrm{a}$ & $\mathrm{n} / \mathrm{a}$ & $\begin{array}{c}45.30 \\
{[37.75-54.36]}\end{array}$ & $\begin{array}{c}364.27 \\
{[43.20-3071.30]}\end{array}$ \\
\hline $\begin{array}{l}\text { Access block duration }>1 \mathrm{hr}(\mathrm{ABD} 1) \\
\text { (yes v. no) }\end{array}$ & $\mathrm{n} / \mathrm{a}$ & $\mathrm{n} / \mathrm{a}$ & $\begin{array}{c}22.39 \\
{[18.67-26.87]}\end{array}$ & $\begin{array}{c}217.27 \\
{[30.62-1541.63]}\end{array}$ \\
\hline CTAS 1 v. CTAS 2-5 & $\mathrm{n} / \mathrm{a}$ & $\mathrm{n} / \mathrm{a}$ & NS & $\begin{array}{c}0.47 \\
{[0.30-0.74]}\end{array}$ \\
\hline
\end{tabular}

the ICU: 1) zero-consult, 2) one-consult, or 3) twoconsult. The zero-consult ICU admission was from the "direct" population; because Sunnybrook is a regional trauma and stroke centre, teams led by trauma leaders or neurologists "directly" see these critically ill patients in the ED and admit them to ICU with no consultation through the ED. The one-consult ICU admission is referred to the ICU after being assessed by the emergency physician, seen by the ICU service in the ED, and possibly accepted for admission. For the two-consult ICU admission, the emergency physician initially refers the patient to a nonICU service. The consult occurs in the ED. The service 


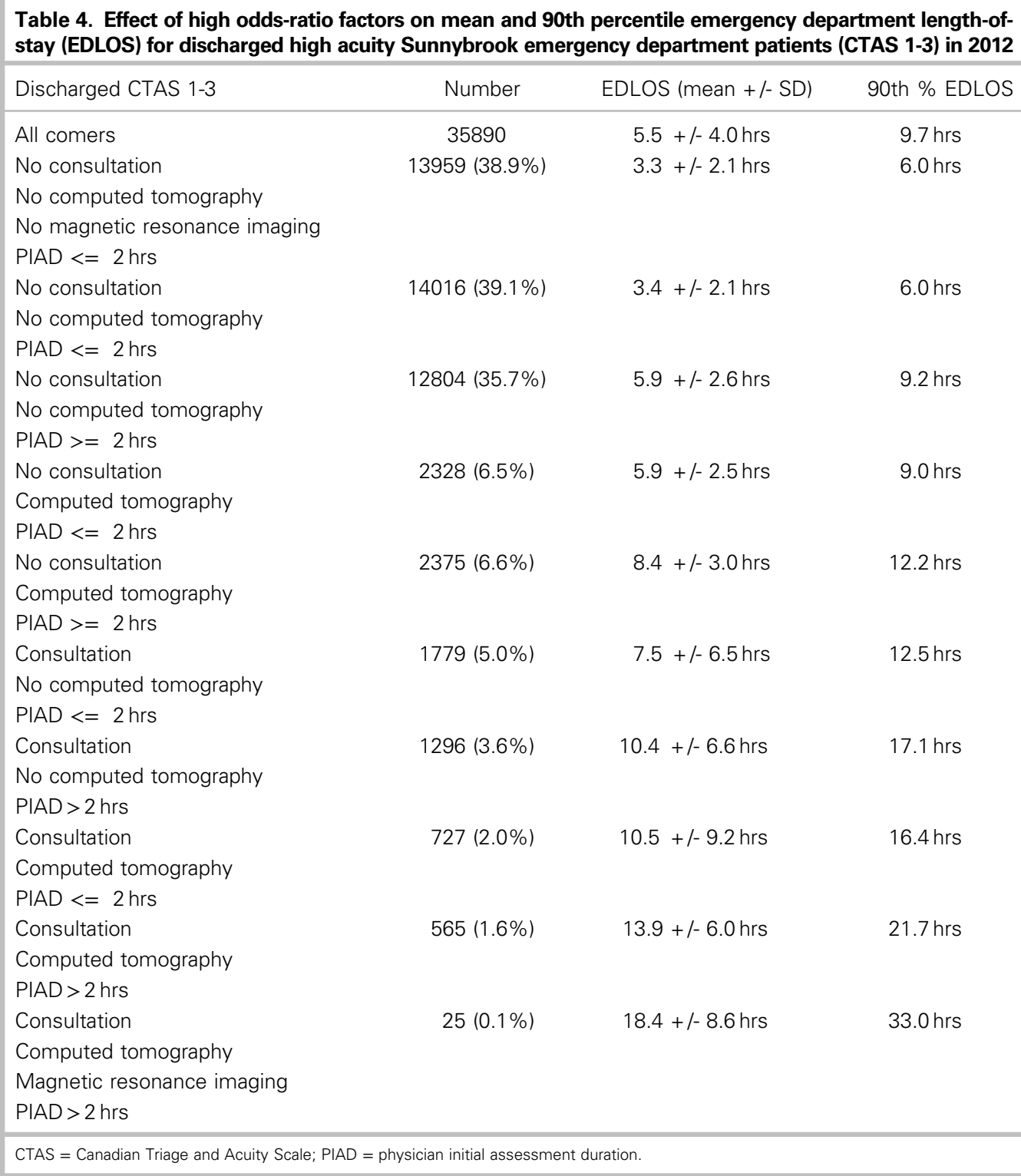

decides whether the patient is too ill for a ward bed and is referred to ICU. The second ICU consult occurs in the $\mathrm{ED}$, and the patient is usually accepted for admission. Zero-, single-, and two-consultations were $20.0 \%, 38.4 \%$, and $41.6 \%$ of ICU admissions, respectively.

Irrespective of the number of consultations, ICU admissions reached Ministry targets if PIAD $\leq 2$ hours, $\mathrm{BRD} \leq 6$ hours, and $\mathrm{AB} \leq 1$ hour. Less than $12 \%$ of ICU admissions fulfilled the criteria and had a 90th percentile EDLOS of 5.8 hours.

Eleven percent of ICU admissions had all three factors. The 90th percentile EDLOS was 37.9 hours. For the two-consultation subgroup, the 90th percentile EDLOS increased to 41.5 hours.
Table 5 outlines the effect of the three high odds ratio factors for all ICU admissions and subgroups.

All ICU admissions increased between January 2015 and October 2016 (Figure 2). Figure 3 is the PDSA run chart. With the loss of four ICU beds, the mean EDLOS shifted above the median, but not the 90th percentile. With the addition of another resident for emergency department ICU consultations and the addition of four transitional ward beds, the mean and 90th percentile EDLOS trended downwards below the median. In the latter months of the cycle, the 90th percentile EDLOS began to reach the 25-hour target. As the volume increased in the later months of 2016, EDLOS began to increase. 
Failure of emergency wait-time targets in the ED

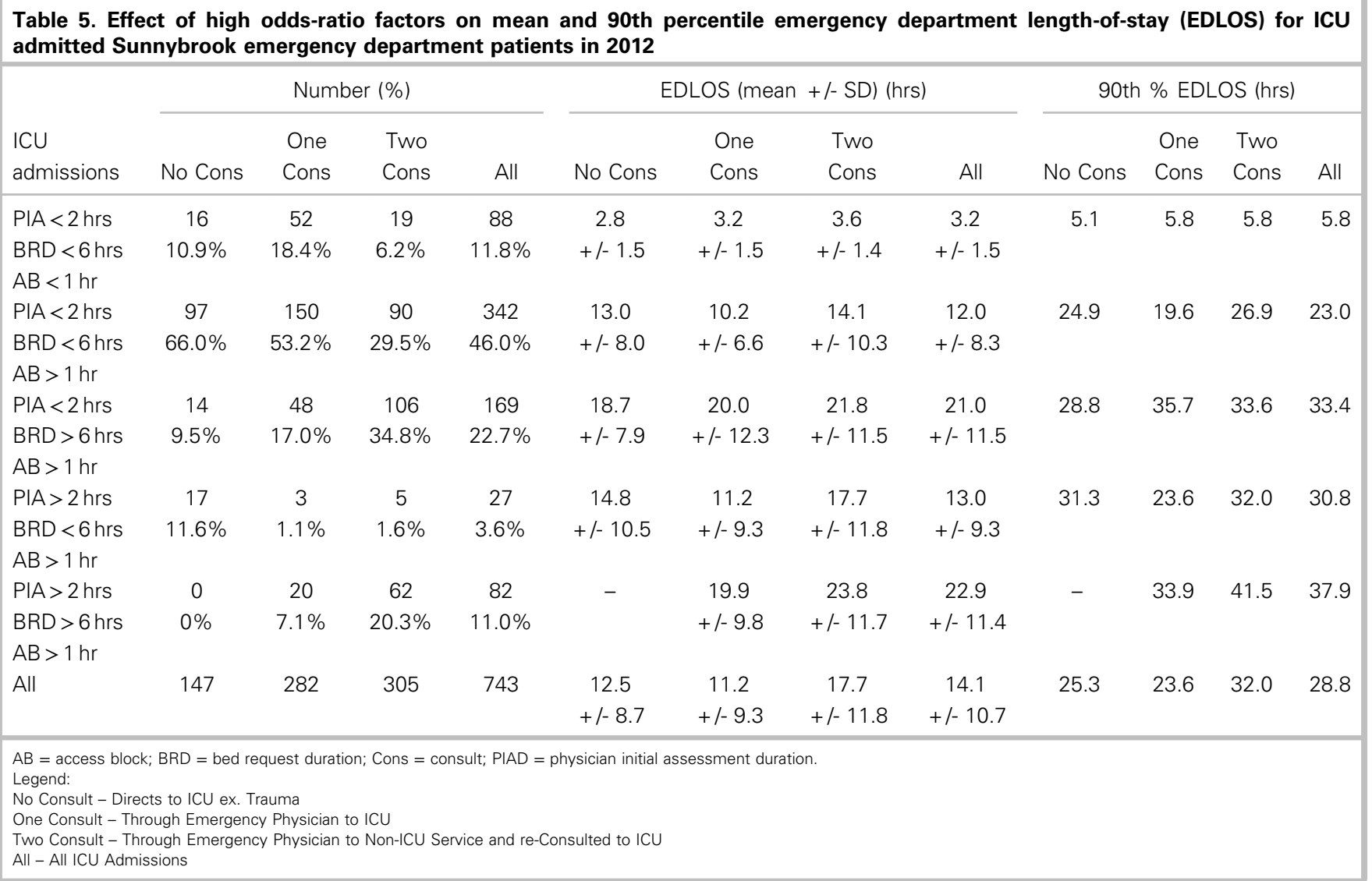

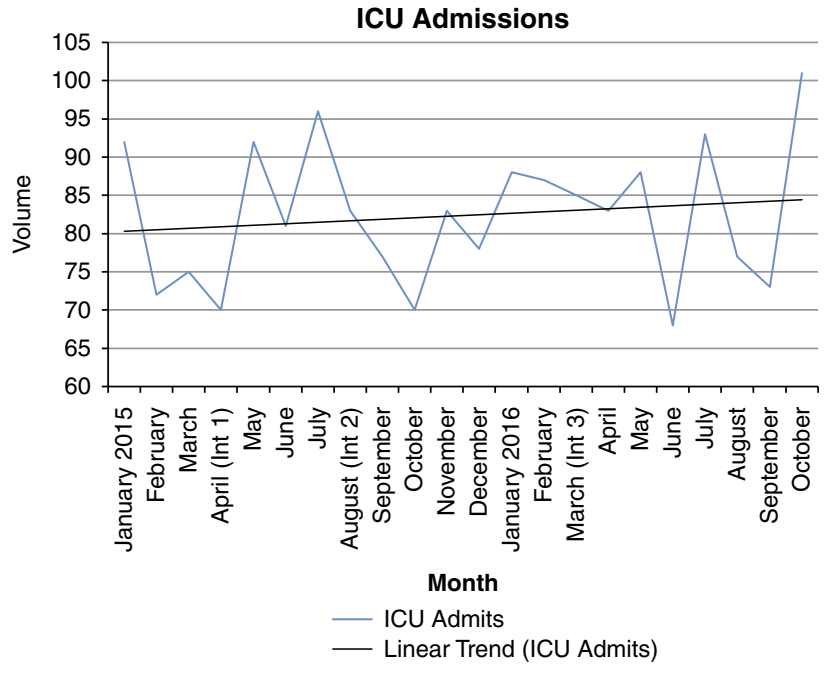

Figure 2. Volume of ICU admissions by month (January 2015 to October 2016). Int 1 (Intervention 1): Loss of 4 ICU beds; Int 2 (Intervention 2): Increase to 2 ICU residents for ED consultations; Int 3 (Intervention 3): Increase of 4 ward transitional beds for ICU transfers.

\section{Discharged low acuity patients}

The factors most strongly associated with failing the 4-hour time target were PIAD $>2$ hours, receiving a consultation, CT scan, MRI, troponin I, or US. Other factors with lower odds ratios included ambulance arrival, night shift, receiving an $\mathrm{X}$-ray, increasing emergency stretcher occupancy with admitted patients, increasing patient age, additional patient arrival per hour, and weekends (see Table 3).

\section{LIMITATIONS}

This study's strength was its large sample size with few missing datapoints; however, there were limitations. User error, such as entering wrong time values, could compromise database accuracy. A solution is to use radiofrequency identification technology, where time stamps are automatically collected during the patient's physician encounter, departure, or admission. We deliberately focused on a single hospital to demonstrate how a hospital can analyse its own administrative databases to find tailored solutions to crowding, which consequently limited generalizability. The model did not include all factors that could affect EDLOS, such as medical student supervision ${ }^{38}$ or staffing. We did not include variables such as elective surgery ${ }^{39}$ or family 


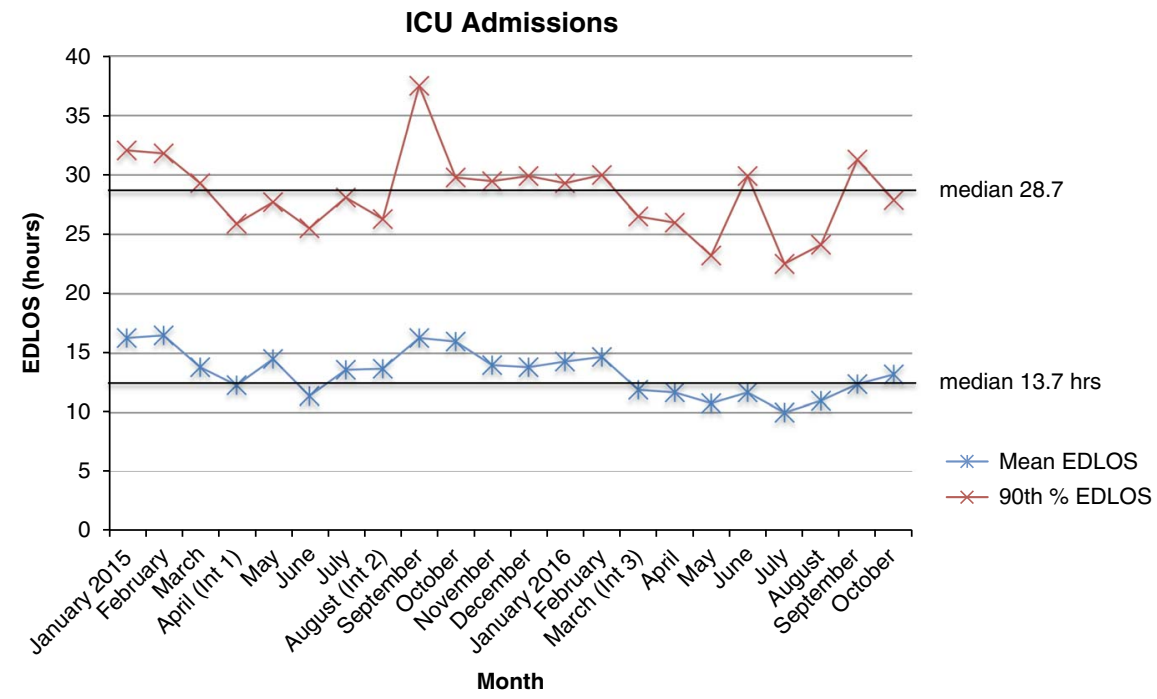

Figure 3. PDSA Cycle Run Chart: Mean and 90th\% EDLOS of ICU Admits by Month. Int 1 (Intervention 1): Loss of 4 ICU beds; Int 2 (Intervention 2): Increase to 2 ICU residents for ED consultations; Int 3 (Intervention 3): Increase of 4 ward transitional beds for ICU transfers.

physician access ${ }^{40}$ given that these were not modifiable by ED operations. For influential factors, comparisons with another hospital or system would provide further context. Finally, the run chart could not determine process stability. ${ }^{41}$

\section{DISCUSSION}

Factors associated with prolonged EDLOS can be divided into input, throughput, output, and system factors. ${ }^{18,19}$ Examples of input factors are increasing patient volumes, ${ }^{4,14}$ complexity, and acuity, ${ }^{4,22}$ and higher expectations on professional health care. ${ }^{14}$ Throughput factors include prolonged specialty consultation turnaround times, ${ }^{20,42}$ delays in diagnostic services, ${ }^{4,20,43}$ increased demand for high technology, ${ }^{1,22}$ diagnostic testing, ${ }^{8,30}$ mismatched staffing to patient demand, ${ }^{4}$ variations in physician decision-making, ${ }^{4,20}$ communication and cultural barriers with patients, ${ }^{4,44}$ and computerized order entry. ${ }^{4,45}$ Output factors include $\mathrm{AB}$ or limited access to alternate level care beds. ${ }^{20}$ Finally, in the United States, systems factors include the avoidance of an expensive admission by "intensive therapy" in the $\mathrm{ED}^{4,22}$ to save the hospital resources. Educational models in academic centers ${ }^{46}$ require patients to be seen by multi-level trainees before management is complete, resulting in increased EDLOS. Given the multitude of factors associated with prolonged EDLOS, which one should a hospital prioritize?
Factors associated with failing Ontario government EDLOS targets at Sunnybrook were determined. For high acuity discharges, factors strongly associated with failing to meet EDLOS targets were potentially modifiable at the physician/hospital-level: waiting to see an emergency physician for more than 2 hours, requesting consultations and the use of advanced diagnostic imaging (CT, MRI, US), troponin I. For ICU admissions, factors were hospital-controlled: bed request and $\mathrm{AB}$ duration.

These findings are concordant with previously published results from a small, retrospective chart review in $1999^{47}$ and a comprehensive 2006 - 2008 study of the American National Hospital Ambulatory Medical Care Survey (NHAMCS) by Kocher et al. ${ }^{30}$ However, the NHAMCS study's limitation was the inability to generalize its results to individual hospitals because of differences that exist between them. Kocher et al. recommended that each hospital examine its patient population to determine bottlenecks for quality improvement. With this study, we have been able to incorporate multiple factors that have been outlined in the literature $24,30,47-50$ and apply them to Sunnybrook. We deliberately chose factors that are routinely collected such that they could be readily used for Sunnybrook quality improvement initiatives.

If the hospital's operations focus on strongly associated factors, there are evidence-informed interventions available. For example, CT and US imaging volume 
can be decreased by best-practice guidelines and team approach. ${ }^{51-53}$ Eliminating oral contrast speeds up abdominal CT scans and shortens EDLOS. ${ }^{54}$ Consultation processes and EDLOS can be shortened by a computer management system, ${ }^{55}$ dedicated emergency consultation teams, ${ }^{53,56}$ or by communicating daily performance metrics. ${ }^{42}$ Physician-triage shortens PIAD. ${ }^{57-60}$ In some settings, point-of-care troponin I or stat laboratory can shorten EDLOS. ${ }^{61-65}$ Interventions to manage $\mathrm{AB}$ include early hospital discharges, ${ }^{66}$ streaming, ${ }^{67}$ full-capacity protocols, ${ }^{68,69}$ and medical assessment units. $^{70}$

It is important to understand Sunnybrook's EDLOS in the context of its population, programs, and complexity. ${ }^{71}$ Compared to the rest of Ontario, Sunnybrook has more admissions, consultations, and CT scans. Because Sunnybrook is a regional trauma, stroke, neurosurgical, and oncology centre with an elderly patient population, more hospital resources are required to care of its complex ED population. Sunnybrook admission rate is high because of its acuity. In $2012,87.7 \%$ of patients were CTAS 1 to 3 with $4.6 \%$ being CTAS 1 . In comparison, $58.4 \%$ of all Ontario ED visits were CTAS 1 to 3 , and $0.7 \%$ was CTAS $1 .{ }^{72}$ Sunnybrook's admission rate was $22 \%$, which was three times greater than Ontario's rate of $7.0 \% .^{72}$

In 2012, the Ontario CT rate was $5.9 \%,{ }^{73}$ whereas Sunnybrook's was $20 \%$. CTs have become an essential diagnostic tool to provide quality patient care. ${ }^{74}$ Between 1996 and 2007, American CT use in EDs had increased by $330 \%{ }^{75}$ and associated with a decrease in admissions. As discussed earlier, a hospital can save money by providing "intensive therapy" and diagnostics in the emergency department ${ }^{4,22}$ to avoid admissions. Consequently, to stop ordering CT scans in the ED may be an intervention with unintended consequences. Such a policy could increase the number of avoidable admissions or discharge patients with incorrect diagnosis, leading to increased morbidity or mortality. This is not to say that the increasing diagnostic demand should not be examined. There is a need to decrease the number of CTs and diagnostics being ordered. ${ }^{75}$ More research is required to ensure that CTs and other diagnostics are ordered to maximize patient benefit and minimize risk and cost.

Could EDLOS reflect the patient complexity and associated hospital resource consumption, rather than process inefficiencies? This study hints that the relationship between patient complexity, hospital resource use, EDLOS, disposition, and CTAS is unclear. Consequently, should government targets be changed to incorporate these relationships? Further scrutiny of the Ministry pay-for performance targets based on CTAS groupings and disposition is suggested.

The largest contributing factor for Sunnybrook ICU and all admissions' failure to reach EDLOS targets was AB. ${ }^{5,8,20,22,23-29}$ In 2012, ward bed capacity for acute admissions decreased from 351 to 341 beds, and average hospital occupancy was $97.6 \%$. Sunnybrook ICU had 58 beds with an occupancy of $96 \%$. The daily average occupancy level of Sunnybrook's 36 emergency stretchers with admitted patients was $51.8 \%$. The unintended consequence is multiple management pathways for admissions, including the critically ill. Prolonged EDLOS is associated with higher mortality, longer inpatient length of stay, and higher cost. ${ }^{34,76}$ Therefore, one of the solutions to reach government targets is to balance the supply-demand for hospital resources.

The run chart reflects the influence of $\mathrm{AB}, \mathrm{BRD}$, and tailored Sunnybrook interventions. Losing four ICU beds exacerbated $\mathrm{AB}$ and increased EDLOS. The ICU decreased BRD by increasing the manpower for ED ICU consultations. Four ward transitional beds were added to mitigate AB. Subsequently, the mean and 90th percentile EDLOS decreased, despite increasing ICU admissions. The 90th percentile target was almost reached; however, increasing volumes may explain the inability to achieve the target. Therefore, interventions addressing high influence factors, $\mathrm{AB}$ and $\mathrm{BRD}$, shortened the mean and 90th percentile EDLOS.

In summary, this study found that the high-impact factors predicting Sunnybrook's failure to reach Ministry EDLOS targets were hospital-controlled. Hospitals with complex patients requiring more resources will have prolonged EDLOS if demand is not adequately supported. Evidence-informed solutions to factors highly associated with time target failure are an approach to shorten EDLOS. Hospital quality improvement plans are encouraged to tailor their approach for shortening EDLOS by examining its patient population and resource demands.

\section{REFERENCES}

1. Pines JM, Hilton JA, Weber EJ, et al. International perspectives on emergency department crowding. Acad Emerg Med 2011;18(12):1358-70. 
2. Di Somma S, Paladino L, Vaughan L, et al. Overcrowding in emergency department: an international issue. Intern Emerg Med 2015;10(2):171-5.

3. Morris ZS, Boyle A, Beniuk K, et al. Emergency department crowding: towards an agenda for evidence-based intervention. Emerg Med 7 2012;29(6):460-6.

4. Derlet RW, Richards JR. Overcrowding in the nation's emergency departments: complex causes and disturbing effects. Ann Emerg Med 2000;35(1):63-8.

5. Innes G. Sorry - we're full! Access block and accountability failure in the health care system. CFEM 2015;17(2): 171-9.

6. Pines JM, Pilgrim RL, Schneider SM, et al. Practical implications of implementing emergency department crowding interventions: summary of a moderated panel. Acad Emerg Med 2011;18(12):1278-82.

7. Wiler JL, Griffey RT, Olsen T. Review of modeling approaches for emergency department patient flow and crowding research. Acad Emerg Med 2011;18(12):1371-9.

8. Forero R, McCarthy S, Hillman K. Access block and emergency department overcrowding. Crit Care 2011; 15(216):1-6.

9. Forero R, Hillman KM, McCarthy S, et al. Access block and ED overcrowding. Emerg Med Australas 2010;22(2): 119-35.

10. Bernstein SL, Aronsky D, Duseja R, et al. The effect of emergency department crowding on clinically oriented outcomes. Acad Emerg Med 2009;16(1):1-10.

11. Hoot NR, Aronsky D. Systematic review of emergency department crowding: causes, effects, and solutions. Ann Emerg Med 2008;52(2):126-36.

12. Kelen G, Peterson S, Pronovost P. In the name of patient safety, let's burden the emergency department more. Ann Emerg Med 2016;67(6):737-40.

13. Ackroyd-Stolarz S, Read Guernsey J, Mackinnon NJ, et al. The association between a prolonged stay in the emergency department and adverse events in older patients admitted to hospital: a retrospective cohort study. BM7 Qual Saf 2011; 20(7):564-9.

14. Mason S. Keynote address: United Kingdom experiences of evaluating performance and quality in emergency medicine. Acad Emerg Med 2011;18(12):1234-8.

15. Schuur JD, Venkatesh AK. The price of waiting: what can a province buy for \$109 million? [Editorial]. Ann Emerg Med 2016;67(4):506-8.

16. Wylie K, Crilly J, Toloo GS, et al. Review article: emergency department models of care in the context of care quality and cost: a systematic review. Emerg Med Australas 2015;27(2):95-101.

17. McCarthy ML, Ding R, Pines JM, et al. Comparison of methods for measuring crowding and its effects on length of stay in the emergency department. Acad Emerg Med 2011; 18(12):1269-77.

18. Handel D, Epstein S, Khare R, et al. Interventions to improve the timeliness of emergency care. Acad Emerg Med 2011;18(12):1295-302.

19. Asplin BR, Magid DJ, Rhodes KV, et al. A conceptual model of emergency department crowding. Ann Emerg Med 2003;42(2):173-80.
20. Schull MJ, Slaughter PM, Redelmeier DA. Urban emergency department overcrowding: defining the problem and eliminating misconceptions. C7EM 2002; 4(2):76-83

21. Durand AC, Palazzolo S, Tanti-Hardouin N, et al. Nonurgent patients in emergency departments: rational or irresponsible consumers? Perceptions of professionals and patients. BMC Res Notes 2012;5:525.

22. Pitts SR, Pines JM, Handrigan MT, et al. National trends in emergency department occupancy, 2001 to 2008: effect of inpatient admissions versus emergency department practice intensity. Ann Emerg Med 2012;60(6):679-86.e3.

23. Bond K, Ospina MB, Blitz S, et al. Frequency, determinants and impact of overcrowding in emergency departments in Canada: a national survey. Healthc Q 2007;10(4): 32-40.

24. Forster AJ, Stiell I, Wells G, et al. The effect of hospital occupancy on emergency department length of stay and patient disposition. Acad Emerg Med 2003;10(2):127-33.

25. Cunningham $P$, Sammut J. Inadequate acute hospital beds and the limits of primary care and prevention. Emerg Med Australas 2012;24(5):566-72.

26. Lucas R, Farley H, Twanmoh J, et al. Emergency department patient flow: the influence of hospital census variables on emergency department length of stay. Acad Emerg Med 2009;16(7):597-602.

27. McCarthy ML, Zeger SL, Ding R, et al. Crowding delays treatment and lengthens emergency department length of stay, even among high-acuity patients. Ann Emerg Med 2009;54(4):492-503.e4.

28. Felton BM, Reisdorff EJ, Krone $\mathrm{CN}$, et al. Emergency department overcrowding and inpatient boarding: a statewide glimpse in time. Acad Emerg Med 2011;18(12):1386-91.

29. Schiff GD. System dynamics and dysfunctionalities: levers for overcoming emergency department overcrowding. Acad Emerg Med 2011;18(12):1255-61.

30. Kocher KE, Meurer WJ, Desmond JS, et al. Effect of testing and treatment on emergency department length of stay using a national database. Acad Emerg Med 2012; 19(5):525-34.

31. Boyle A. Crowding in emergency departments: guidance from CEM emphasises system-wide solutions. [Editorial]. Emerg Med 7 2015;32(2):92.

32. Richardson DB. Reducing patient time in the emergency department. Med 7 Aust 2003;179(10):516-7.

33. Gilson L. Health policy and systems research: a methodology reader. Alliance for Health Policy and Systems Research; 2012. Available at: http://www.who.int/alliancehpsr/alliancehpsr_reader.pdf.

34. Chalfin DB, Trzeciak S, Likourezos A, et al. Impact of delayed transfer of critically ill patients from the emergency department to the intensive care unit. Crit Care Med 2007; 35(6):1477-83.

35. Beveridge R. CAEP issues. The Canadian Triage and Acuity Scale: a new and critical element in health care reform. Canadian Association of Emergency Physicians. 7 Emerg Med 1998;16(3):507-11.

36. Ontario Ministry of Health and Long-Term Care. Ontario wait times - Ontario's emergency room wait time strategy; 
2016. Available at: http://www.health.gov.on.ca/en/pro/pro grams/waittimes/edrs/strategy.aspx.

37. Pitts SR. Higher-complexity ED billing codes - sicker patients, more intensive practice, or improper payments. N Engl 7 Med 2012;367(26):2465-7.

38. Gerbeaux P, Ledoray V, Liauthaud H, et al. Medical student effect on emergency department length of stay. Ann Emerg Med 2001;37(3):275-8.

39. Rathlev NK, Chessare J, Olshaker J, et al. Time series analysis of variables associated with daily mean emergency department length of stay. Ann Emerg Med 2007;49(3):265-71.

40. Moineddin R, Meaney C, Agha M, et al. Modeling factors influencing the demand for emergency department services in Ontario: a comparison of methods. BMC Emerg Med 2011;11(13):1-14.

41. Perla RJ, Provost LP, Murray SK. The run chart: a simple analytical tool for learning from variation in healthcare processes. BMJ Qual Saf 2011;20(1):46-51.

42. Horng S, Pezzella L, Tibbles CD, et al. Prospective evaluation of daily performance metrics to reduce emergency department length of stay for surgical consults. 7 Emerg Med 2013;44(2):519-25.

43. Kanzaria HK, Probst MA, Ponce NA, et al. The association between advanced diagnostic imaging and ED length of stay. Am 7 Emerg Med 2014;32(10):1253-8.

44. Bekmezian A, Chung PJ, Cabana MD, et al. Factors associated with prolonged emergency department length of stay for admitted children. Pediatr Emerg Care 2011;27(2):110-5.

45. Gray A, Fernandes CM, Van Aarsen K, et al. The impact of computerized provider order entry on emergency department flow. CFEM 2016;18(4):264-9.

46. Weber EJ. Practicing what we teach: in order to teach patient-centered care, we need to deliver it. Acad Med 2015;90(1):14-5.

47. Yoon P, Steiner I, Reinhardt G. Analysis of factors influencing length of stay in the emergency department. CFEM 2003;5(3):155-61.

48. Möckel M, Searle J, Hüttner I, et al. Qualitative process analysis and modelling of emergency care workflow and interface management: identification of critical process steps. Eur 7 Emerg Med 2015;22(2):79-86.

49. Fogarty EM, Cummins F. The effect of admitted patients in the emergency department on rates of hospital admissions. Emerg Med 7 2013;30(9):766-7.

50. Glasser JS, Zacher LL, Thompson JC, et al. Determination of the internal medicine service's role in emergency department length of stay at a military medical center. Mil Med 2009;174(11):1163-6.

51. Kharbanda AB, Madhok M, Krause E, et al. Implementation of electronic clinical decision support for pediatric appendicitis. Pediatrics 2016;137(5):e1-9.

52. Russell WS, Schuh AM, Hill JG, et al. Clinical practice guidelines for pediatric appendicitis evaluation can decrease computed tomography utilization while maintaining diagnostic accuracy. Pediatr Emerg Care 2013;29(5):568-73.

53. Suen K, Hayes IP, Thomson BN, et al. Effect of the introduction of an emergency general surgery service on outcomes from appendicectomy. Br 7 Surg 2014;101(1):e141-6.
54. Schuur JD, Chu G, Sucov A. Effect of oral contrast for abdominal computed tomography on emergency department length of stay. Emerg Radiol 2010;17(4):267-73.

55. Cho SJ, Jeong J, Han S, et al. Decreased emergency department length of stay by application of a computerized consultation management system. Acad Emerg Med 2011; 18(4):398-402.

56. Qureshi A, Smith A, Wright F, et al. The impact of an acute care emergency surgical service on timely surgical decisionmaking and emergency department overcrowding. $7 \mathrm{Am}$ Coll Surg 2011;213(2):284-93.

57. Cheng I, Lee J, Mittmann N, et al. Implementing wait-time reductions under Ontario government benchmarks (Pay-for-Results): a Cluster Randomized Trial of the Effect of a Physician-Nurse Supplementary Triage Assistance team (MDRNSTAT) on emergency department patient wait times. BMC Emerg Med 2013;13(17):1-10.

58. Han JH, France DJ, Levin SR, et al. The effect of physician triage on emergency department length of stay. 7 Emerg Med 2010;39(2):227-33.

59. Holroyd BR, Bullard MJ, Latoszek K, et al. Impact of a triage liaison physician on emergency department overcrowding and throughput: a randomized controlled trial. Acad Emerg Med 2007;14(8):702-8.

60. Abdulwahid MA, Booth A, Kuczawski M, et al. The impact of senior doctor assessment at triage on emergency department performance measures: systematic review and meta-analysis of comparative studies. Emerg Med 7 2016; 33(7):504-13.

61. Loten C, Attia J, Hullick C, et al. Validation of a point of care troponin assay in real life emergency department conditions. Emerg Med Australas 2009;21(4):286-92.

62. Koehler J, Flarity K, Hertner G, et al. Effect of troponin I point-of-care testing on emergency department throughput measures and staff satisfaction. Adv Emerg Nurs 7 2013; 35(3):270-7.

63. Ryan RJ, Lindsell CJ, Hollander JE, et al. A multicenter randomized controlled trial comparing central laboratory and point-of-care cardiac marker testing strategies: the Disposition Impacted by Serial Point of Care Markers in Acute Coronary Syndromes (DISPO-ACS) trial. Ann Emerg Med 2009;53(3):321-8.

64. Singer AJ, Ardise J, Gulla J, et al. Point-of-care testing reduces length of stay in emergency department chest pain patients. Ann Emerg Med 2005;45(6):587-91.

65. Singer AJ, Viccellio P, Thode HCJ, et al. Introduction of a stat laboratory reduces emergency department length of stay. Acad Emerg Med 2008;15(4):324-8.

66. Khanna S, Boyle J, Good N, et al. Early discharge and its effect on ED length of stay and access block. Stud Health Technol Inform 2012;178:92-8.

67. Lowthian J, Curtis A, Straney L, et al. Redesigning emergency patient flow with timely quality care at the Alfred. Emerg Med Australas 2015;27(1):35-41.

68. ACEP Task Force Report on Boarding. Emergency department crowding: high-impact solutions. American College of Emergency Physicians; 2008. Available at: http://californiaacep.org/ wp-content/uploads/Emergency_Department_Crowding_ High_Impact_Solutions_ACEP_Task_Force_on_Boarding_ April_2008.pdf 
69. Villa-Roel C, Guo X, Holroyd BR, et al. The role of full capacity protocols on mitigating overcrowding in EDs. Am $\mathcal{F}$ Emerg Med 2012;30(3):412-20.

70. Scott I, Vaughan L, Bell D. Effectiveness of acute medical units in hospitals: a systematic review. Int 7 Qual Health Care 2009;21(6):397-407.

71. Taylor SL, Dy S, Foy R, et al. What context features might be important determinants of the effectiveness of patient safety practice interventions? BM7 Qual Saf 2011;20(7): 611-7.

72. Canadian Institute for Health Information. Highlights of 20112012 emergency department visits and inpatient hospitalizations; 2013.
73. Berdahl CT, Vermeulen MJ, Larson DB, et al. Emergency department computed tomography utilization in the United States and Canada. Ann Emerg Med 2013;62(5):486-94.e3.

74. Pandharipande PV, Reisner AT, Binder WD, et al. CT in the emergency department: A real-time study of changes in physician decision making. Radiology 2016;278(3):812-21.

75. Kocher KE, Meurer WJ, Fazel R, et al. National trends in use of computed tomography in the emergency department. Ann Emerg Med 2011;58(5):452-62.e3.

76. Duke GJ, Buist $\mathrm{MD}$, Pilcher $\mathrm{D}$, et al. Interventions to circumvent intensive care access block: a retrospective 2-year study across metropolitan Melbourne. Med 7 Aust 2009;190(7):375-8. 